\title{
A PERIODIZAÇÃO DO DESENVOLVIMENTO PSICOLÓGICO INDIVIDUAL NA PERSPECTIVA DE LEONTIEV, ELKONIN E VIGOSTSKI
}

\author{
Marilda Gonçalves Dias Facci ${ }^{*}$
}

\begin{abstract}
RESUMO: Este estudo se propõe a analisar algumas contribuições da psicologia de Leontiev, Elkonin e Vigotski no campo da psicologia do desenvolvimento, mais especificamente a questão da periodização da ontogênese humana. Leontiev e Elkonin, seguindo a linha sóciohistórica ou histórico-cultural iniciada por Vigotski, desenvolveram as bases de uma psicologia do desenvolvimento que superasse o enfoque naturalizante tão forte nesse campo. Segundo eles cada período do desenvolvimento individual humano é caracterizado por uma atividade principal, ou atividade dominante, a partir da qual se estruturam as relações do indivíduo com a realidade social. São analisados também os períodos que Leontiev e Elkonin detectaram no desenvolvimento dos indivíduos nas condições sociais da URSS.
\end{abstract}

Palavras-chave: Psicologia do desenvolvimento. Leontiev. Elkonin. Atividade principal.

\section{THE STAGES OF THE PSYCHOLOGICAL DEVELOPMENT OF INDIVIDUALS ACCORDING to LeONTYeV, ELKONIN AND VyGOTSKY}

ABSTRACT: This study analyses certain contributions by Leontyev, Elkonin and Vigostky in the area of Developmental Psychology, more particularly the stages of human ontogenesis. Adopting the social-historical/historical-cultural approach initiated by Vygotsky, Leontyev and Elkonin formulated the basis for a Developmental Psychology that endeavored to surpass the naturalistic approach that prevailed in this field. According to these authors, each stage of the process of development is characterized by a leading activity from which stems the relationship between the individual and their

Professora do Departamento de Psicologia da Universidade Estadual de Maringá (UEM) e coordenadora do Grupo de Pesquisa "Psicologia Histórico-Cultural e Educação". E-mail: nmfacci@wnet.com.bre mgdfacci@uem.br 
social reality. This study also analyzes the stages of the individual development Leontyev and Elkonin observed under the social conditions of the USSR.

Key words: Developmental psychology. Leontyev. Elkonin. Leading activity.

$\mathcal{E}$ ste estudo se propõe a apresentar alguns aspectos relacionados à periodização do desenvolvimento humano na abordagem histórico-cultural ou sócio-histórica. Nossa formação em psicologia, a atuação no contexto educacional e, principalmente, os estudos que vimos desenvolvendo dos trabalhos de L. S. Vigotski ${ }^{1}$ nos têm conduzido à compreensão do psiquismo humano para além de explicaçôes baseadas em modelos mecanicistas ou modelos organicistas de desenvolvimento, utilizando uma classificação de Palácius (1995).

A psicologia histórico-cultural teve início com as obras de Vigotski (1896-1934). Este pesquisador desenvolveu seu trabalho com base marxista e era "radical", por querer ir à raiz de todos os problemas e por se manter fiel a um método de compreensão do psiquismo humano. Concordamos com Tuleski (2002) e com Duarte $(1996,2000)$ quando afirmam que é necessário manter essa filiação teórica da psicologia histórico-cultural, a qual tem uma visão historicizadora do psiquismo humano.

De acordo com Shuare (1990), os fundamentos marxistas enfatizam que mudanças históricas na sociedade e na vida material produzem mudanças na consciência e no comportamento humano. Existe um desenvolvimento histórico dos fenômenos psíquicos e estes mantêm uma relação de dependência essencial com respeito à vida e à atividade social. Para essa autora, a história da psique humana é a história da sua construção, portanto a psique não é imutável ou invariável no decorrer do desenvolvimento histórico.

Nessa perspectiva, o traço fundamental do psiquismo humano é que este se desenvolve por meio da atividade social, a qual, por sua vez, tem como traço principal a mediação por meio de instrumentos que se interpõem entre o sujeito e o objeto de sua atividade. As funções psicológicas superiores (tipicamente humanas, tais como a atenção voluntária, memória, abstração, comportamento intencional etc.) são produtos da atividade cerebral, têm uma base biológica, mas, fun- 
A periodização do desenvolvimento psicológico individual na perspectiva...

damentalmente, são resultados da interação do indivíduo com o mundo, interação mediada pelos objetos construídos pelos seres humanos.

A constituição dessas funções é caracterizada pela mediação por intermédio dos signos, sendo que a linguagem é o sistema de signos mais importante. As formas superiores de comportamento formaram-se graças ao desenvolvimento histórico da humanidade e originam-se na coletividade em forma de relações entre os homens, e só depois se convertem em funções psíquicas da personalidade. Davidov \& Shuare (1987) esclarecem que no desenvolvimento psíquico do homem há primazia do princípio social sobre o princípio natural-biológico. Para esses autores, o desenvolvimento ontogenético da psique é determinado pelos processos de apropriação das formas históricas e sociais da cultura.

Essas idéias são fundamentais quando se busca compreender a formação do psiquismo humano numa perspectiva historicizadora. Leontiev e Elkonin, neste sentido, conforme Duarte (1996), lançam instigantes questôes a serem discutidas e investigadas na direção da construção de uma psicologia do desenvolvimento efetivamente histórico-social. Esses aspectos constituem a base da discussão neste trabalho.

\section{As atividades principais no desenvolvimento humano}

É necessário superar a visão idealista do desenvolvimento psicológico. Como Vigotski afirmou nos anos de 1930, é imprescindível estudar a afetividade e o intelecto como unidade e não é mais pertinente abordar o desenvolvimento psíquico como um mecanismo adaptativo do comportamento, como Freud e Piaget o faziam: este, por colocar o intelecto como um mecanismo de adaptação da criança ao mundo das coisas; aquele, por apontar os mecanismos de repressão, censura etc. como mecanismos de adaptação ao mundo das pessoas (Elkonin, 1987). A superação dessa visão idealista implica compreender a relação da criança com a sociedade construída historicamente a partir das necessidades dos homens.

Elkonin e Leontiev afirmam que cada estágio de desenvolvimento da criança é caracterizado por uma relação determinada, por uma atividade principal $^{2}$ que desempenha a função de principal forma de relacionamento da criança com a realidade. Para esses estudiosos, o homem - a partir do desenvolvimento de suas atividades, tal 
como elas se formam nas condições concretas dadas de sua vida - adapta-se à natureza, modifica-a, cria objetos e meios de produção desses objetos, para suprir suas necessidades. A criança, nesse caso, por meio dessas atividades principais, relaciona-se com o mundo, e, em cada estágio, formam-se nela necessidades específicas em termos psíquicos. Leontiev (1987) enfatiza que o desenvolvimento dessa atividade condiciona as mudanças mais importantes nos processos psíquicos da criança e nas particularidades psicológicas da sua personalidade.

Segundo Elkonin (1987), os principais estágios de desenvolvimento pelos quais os sujeitos passam são: comunicação emocional do bebê; atividade objetal manipulatória; jogo de papéis; atividade de estudo; comunicação íntima pessoal; e atividade profissional/estudo. A comunicação emocional direta dos bebês com os adultos é a atividade principal desde as primeiras semanas de vida até mais ou menos um ano, constituindo-se como base para a formação de ações sensóriomotoras de manipulação. Na relação da criança com a sociedade, num processo de assimilação das tarefas e dos motivos da atividade humana e das normas de relacionamento que as pessoas estabelecem durante suas relações, o bebê utiliza vários recursos para se comunicar com os adultos, como o choro, por exemplo, para demonstrar as sensações que está tendo e o sorriso para buscar uma forma de comunicação social. Conforme Zaporózhets (1987), o sentimento de amor filial, a simpatia por outras pessoas, o afeto amistoso, entre outros aspectos presentes na relação do bebê com outras crianças e o adulto, são enriquecidos e transformados no processo evolutivo da criança, tornando-se a base indispensável para o surgimento de sentimentos sociais mais complexos.

Já no primeiro ano de vida, a conduta da criança começa a reestruturar-se e cada vez mais aparecem processos de comportamento em virtude das condiçóes sociais e da influência educativa das pessoas que a rodeiam. Para Vygotski (1996), há no primeiro ano de vida uma sociabilidade totalmente específica e peculiar em razão de uma situação social de desenvolvimento única, determinada por dois momentos fundamentais: o primeiro consiste na total incapacidade biológica, pois o bebê é incapaz de satisfazer quaisquer das suas necessidades básicas de sobrevivência. São os adultos que cuidam do bebê, e o caminho por intermédio dos adultos é a via principal de atividade da criança nessa idade. Praticamente todo comportamento do bebê 
A periodização do desenvolvimento psicológico individual na perspectiva...

está inserido e entrelaçado com o fator social e o contato da criança com a realidade é socialmente mediado. A segunda peculiaridade que caracteriza a situação social de desenvolvimento no primeiro ano de vida é a seguinte: embora o bebê dependa do adulto, ele ainda carece dos meios fundamentais de comunicação social em forma de linguagem. A forma como a vida do bebê é organizada o obriga a manter uma comunicação máxima com os adultos, porém essa comunicação é uma comunicação sem palavras, muitas vezes silenciosa, uma comunicação de gênero totalmente peculiar. Assim. “(...) o desenvolvimento do bebê no primeiro ano baseia-se na contradição entre a máxima sociabilidade (em razão da situação em que se encontra) e suas mínimas possibilidades de comunicação" (Vygotski, 1996, p. 286).

Em um segundo momento, ainda na primeira infância, a atividade principal passa a ser a objetal-instrumental, na qual tem lugar a assimilação dos procedimentos elaborados socialmente de ação com os objetos e, para que ocorra essa assimilação, é necessário que os adultos mostrem essas ações às crianças. A comunicação emocional dá lugar a uma colaboração prática. Por meio da linguagem, a criança mantém contato com o adulto e aprende a manipular os objetos criados pelos homens, organizando a comunicação e a colaboração com os adultos.

A primeira função da linguagem é a comunicação, um meio de expressão e compreensão entre os homens, que permite o intercâmbio social. Até mais ou menos os 18 meses, a criança ainda não consegue descobrir as funçôes simbólicas da linguagem, que é uma operação intelectual consciente e altamente complexa. Por volta dos dois anos, a criança apresenta grande evolução da linguagem, dando início a uma forma totalmente nova de comportamento, exclusivamente humana. Inicia-se a formação da consciência e a diferenciação do "eu" infantil. $\mathrm{O}$ “(...) pensamento da criança evolui em função do domínio dos meios sociais do pensamento, quer dizer, em função da linguagem" (Vygotski, 1993, p. 116). Esta é uma mediação entre o sujeito e o objeto do conhecimento. Dessa forma, o conhecimento e as experiências advindas da prática social podem ser difundidos por todos e apropriados por cada um, por cada sujeito em particular. Embora a linguagem constitua uma forma de comunicação com os adultos, para Elkonin (1987), ela não é a atividade principal nessa etapa de desenvolvimento; sua função maior é auxiliar a criança a compre- 
ender a ação dos objetos, é assimilar os procedimentos, socialmente elaborados, de ação com os objetos.

$\mathrm{Na}$ seqüência, no período pré-escolar, a atividade principal passa a ser o jogo ou a brincadeira. Utilizando-se dessas atividades, a criança apossa-se do mundo concreto dos objetos humanos, poor meio da reprodução das ações realizadas pelos adultos com esses objetos. As brincadeiras das crianças não são instintivas e o que determina seu conteúdo é a percepção que a criança tem do mundo dos objetos humanos. A criança opera com os objetos que são utilizados pelos adultos e, dessa forma, toma consciência deles e das açôes humanas realizadas com eles. A criança, durante o desenvolvimento dessa consciência do mundo objetivo, por meio da brincadeira “(...) tenta integrar uma relação ativa não apenas com as coisas diretamente acessíveis a ela, mas também com o mundo mais amplo, isto é, ela se esforça para agir como um adulto" (Leontiev, 1998b, p. 121). Ela ainda não dominou e não pode dominar as operações exigidas pelas condições objetivas reais da ação dada, como, por exemplo, dirigir um carro, andar de motocicleta, pilotar um avião. Mas, na brincadeira, na atividade lúdica, ela pode realizar essa ação e resolve a contradição entre a necessidade de agir, por um lado, e a impossibilidade de executar as operações exigidas pela ação, de outro.

O principal significado do jogo, para Elkonin (1987), é permitir que a criança modele as relações entre as pessoas. $\mathrm{O}$ jogo é influenciado pelas atividades humanas e pelas relações entre as pessoas e o conteúdo fundamental é o homem - a atividade dos homens e as relações com os adultos. Ao mesmo tempo, ele exerce influência sobre o desenvolvimento psíquico da criança e sobre a formação de sua personalidade: “(...) a evolução do jogo prepara para a transição para uma fase nova, superior, do desenvolvimento psíquico, a transição para um novo período evolutivo" (Elkonin, 1998, p. 421).

No período pré-escolar, o que se constata é que as necessidades básicas da criança são supridas pelos adultos, e as crianças sentem sua dependência com relação a eles. O seu mundo divide-se em dois círculos: um criado pelos pais ou pelas pessoas que convivem com elas, sendo que essas relações determinam as relações com todas as demais pessoas; o outro grupo é formado pelos demais membros da sociedade. Portanto, a vida da criança muda muito quando 
A periodização do desenvolvimento psicológico individual na perspectiva...

ela entra na escola, onde a relação com os professores faz parte de um pequeno e íntimo círculo de seus contatos. A passagem da criança da infância pré-escolar à fase seguinte está condicionada, então, pela entrada da criança na escola e a atividade principal passa a ser $o$ estudo. Conforme Leontiev (1978), o próprio lugar que a criança ocupa com relação ao adulto se torna diferente. Na escola, a criança tem deveres a cumprir, tarefas a executar e, pela primeira vez em seu desenvolvimento, tem a impressão de estar realizando atividades verdadeiramente importantes.

O estudo serve como intermediário de todo o sistema de relações da criança com os adultos que a cercam, incluindo a comunicação pessoal com a família. Podemos observar várias mudanças que se operam ao redor da criança, dentro mesmo da própria família: os parentes dirigem-se a ela sempre perguntando pela escola, pelos seus estudos; em casa a criança não pode ser importunada pelos irmãos quando está fazendo tarefa etc. Nesta atividade de estudo ocorre a assimilação de novos conhecimentos, cuja direção constitui o objetivo fundamental do ensino.

Para Davidov \& Márkova (1987b, p. 321) a assimilação ou apropriação dos conhecimentos é o processo de reprodução, pelo indivíduo, dos “(...) procedimentos historicamente formados de transformação dos objetos da realidade circundante, dos tipos de relação em direção a isso e do processo de conversão de padrôes, socialmente elaborados, em formas da 'subjetividade' individual". O ensino escolar deve, portanto, nesse estágio, introduzir o aluno na atividade de estudo, de forma que se aproprie dos conhecimentos científicos. Sobre a base dos estudos, conforme Davidov (1988), surgem a consciência e o pensamento teórico e desenvolvem-se, entre outras funções, as capacidades de reflexão, análise e planificação mental.

Uma nova transição é a chegada da adolescência, com uma outra atividade principal: a comunicação intima pessoal entre os jovens. Ocorre uma mudança na posição que o jovem ocupa com relação ao adulto e as suas forças físicas, juntamente com seus conhecimentos e capacidades, colocam-no, em certos casos, em pé de igualdade com os adultos, e, muitas vezes, até superior em alguns aspectos particulares. Ele torna-se crítico em face das exigências que lhe são impostas, das maneiras de agir, das qualidades pessoais dos adultos e também 
dos conhecimentos teóricos. Ele busca, na relação com o grupo, uma forma de posicionamento pessoal diante das questóes que a realidade impõe à sua vida pessoal e social.

A adolescência é o período de desenvolvimento mais crítico e, nessa idade, segundo Elkonin (1987), essa atividade especial no estabelecimento de relações pessoais íntimas entre os adolescentes é uma forma de reproduzir, com os companheiros, as relações existentes entre as pessoas adultas. A interação com os companheiros é mediatizada por determinadas normas morais e éticas (regras de grupo). A atividade de estudo ainda continua sendo considerada importante para os jovens e ocorre, por parte dos alunos, o domínio da estrutura geral da atividade de estudo, a formação de seu caráter voluntário, a tomada de consciência das particularidades individuais de trabalho e a utilização desta atividade como meio para organizar as interações sociais com os companheiros de estudo.

Segundo Vygotski (1996), nessa fase de desenvolvimento se produz no adolescente um importante avanço no desenvolvimento intelectual, formando-se os verdadeiros conceitos. O pensamento por conceito abre para o jovem um mundo da consciência social, e o conhecimento da ciência, da arte e as diversas esferas da vida cultural podem ser corretamente assimiladas. Por meio do pensamento em conceito ele chega a compreender a realidade, as pessoas ao seu redor e a si mesmo. O pensamento abstrato desenvolve-se cada vez mais e o pensamento concreto começa a pertencer ao passado. $\mathrm{O}$ conteúdo do pensamento do jovem converte-se em convicção interna, em orientações dos seus interesses, em normas de conduta, em sentido ético, em seus desejos e seus propósitos.

Por meio da comunicação pessoal com seus iguais, o adolescente forma os pontos de vista gerais sobre o mundo, sobre as relações entre as pessoas, sobre o próprio futuro e estrutura-se o sentido pessoal da vida. Esse comportamento em grupo ainda dá origem a novas tarefas e motivos de atividade dirigida ao futuro, e adquire o caráter de atividade profissionallde estudo. Davidov \& Márkova (1987a) esclarecem que na idade escolar avançada a atividade de estudo passa a ser utilizada como meio para a orientação e preparação profissional, ocorrendo o domínio dos meios de atividade de estudo autônomo, com uma atividade cognoscitiva e investigativa criadora. A etapa final do 
A periodização do desenvolvimento psicológico individual na perspectiva...

desenvolvimento acontece quando o indivíduo se torna trabalhador, ocupando um novo lugar na sociedade.

É a sociedade que determina o conteúdo e a motivação na vida da criança, pois todas as atividades dominantes aparecem como elementos da cultura humana. E, de acordo com as características objetais e de conteúdos das atividades dominantes, identificadas até o presente, essas atividades, segundo Elkonin (1987, p. 121), podem ser divididas em dois grupos: no primeiro grupo estão aquelas atividades desenvolvidas no sistema criança-adulto social, as quais têm orientação predominante na atividade humana e na assimilação de objetivos, motivos e normas das relações entre as pessoas; no segundo grupo estão presentes as atividades que ocorrem num sistema criança-objeto social, no qual ocorre a assimilação de procedimentos de ação com os objetos.

As atividades são dominantes em determinados períodos e, no período seguinte, não deixam de existir, mas vão perdendo sua força. Após os períodos em que tem lugar o desenvolvimento preponderante na esfera motivacional e de necessidades, seguem períodos com preponderância de formação de possibilidades operacionais técnicas. Neste aspecto, Elkonin (1987, p. 122) formula, então, uma hipótese do caráter periódico dos processos de desenvolvimento psíquico e distribui os tipos de atividade em grupos de acordo com a seqüência de atividade principal, obtendo a seguinte série: a) primeira infância: comunicação emocional direta ( ${ }^{\circ}$ grupo) e atividade objetal manipulatória ( $2^{\circ}$ grupo); b) segunda infância: jogo ( $1^{\circ}$ grupo $)$ e atividade de estudo ( $2^{\circ}$ grupo); e c) adolescência: comunicação íntima pessoal $\left(1^{\circ}\right.$ grupo) e atividade profissional de estudo ( $2^{\circ}$ grupo). Cada época consiste em dois períodos regularmente ligados entre si. Tem início com o período em que predomina a assimilação dos objetivos, dos motivos e das normas da atividade e essa etapa prepara para a passagem ao segundo período, no qual ocorrem a assimilação dos procedimentos de ação com o objeto e a formação de possibilidades técnicas e operacionais.

Como ocorre, então, a passagem de uma etapa de desenvolvimento à seguinte? Leontiev (1998a) argumenta que, no decorrer do seu desenvolvimento, a criança começa a se dar conta de que o lugar que ocupava no mundo das relações humanas que a circundava não 
corresponde às suas potencialidades e se esforça para modificá-lo, surgindo uma contradição explícita entre esses dois fatores. Ela torna-se consciente das relações sociais estabelecidas, e essa conscientização a leva a uma mudança na motivação de sua atividade; nascem novos motivos, conduzindo-a a uma reinterpretação de suas ações anteriores. A atividade principal em determinado momento passa a um segundo plano, e uma nova atividade principal surge, dando início a um novo estágio de desenvolvimento.

Essas transições provocam mudanças em ações, operações e funções que, por sua vez, conduzem a mudanças de atividades como um todo. As mudanças observadas nos processos de vida psíquica da criança (percepção, memória, pensamento, entre outras funções psíquicas), dentro do limite de cada estágio, estão ligadas entre si e não são independentes umas das outras. No caso da memória, por exemplo, no período pré-escolar, ela apresentava determinada função, mas quando chega à fase dos estudos, a memória ocupa novo lugar na estrutura da atividade psíquica da criança; a memorização torna-se voluntária e consciente.

Ao abordarmos a questão da atividade principal e do seu significado para o desenvolvimento da criança em determinado período não queremos dizer que, simultaneamente, não exista nenhum desenvolvimento em outras direções. Para Elkonin (1987, p. 122) as atividades da criança são variadas e “(...) seu surgimento e conversão em atividade principal não eliminam as existentes anteriormente, senão que só mudam seu lugar no sistema geral de relações da criança com a realidade, as quais se tornam mais ricas”. A transição de uma etapa de desenvolvimento infantil para outra é caracterizada por crises. Estas surgem no limite entre duas idades e assinalam o fim de uma etapa precedente de desenvolvimento e o começo da seguinte.

Vygotski (1996) identificou as seguintes crises: crises pós-natal - primeiro ano (2 meses-1 ano); crise de 1 ano - infância precoce (1 ano-3 anos); crise de 3 anos - idade pré-escolar (3 anos-7 anos); crise dos 7 anos - idade escolar (8 anos-12 anos); crise dos 13 anos - puberdade (14 anos-18 anos); e crise dos 17 anos. Nesses períodos de crise - que podem durar vários meses, um ano, dois ao máximo - produzem-se mudanças bruscas, rupturas na personalidade da criança. Conforme Vygotski (idem, ibid., p. 256-257), algumas característi- 
A periodização do desenvolvimento psicológico individual na perspectiva...

cas estão presentes nesses períodos: $1^{\text {a }}$.) os limites entre o começo e o final da crise e as idades contíguas são totalmente indefinidas - as crises originam-se de forma imperceptível e é difícil determinar o momento de seu começo e fim; $2^{a}$ ) um grande número de crianças que vivem essa fase são difíceis de educar, elas podem ter conflitos com outras pessoas e consigo mesmas, no entanto não é sempre assim, pois os períodos críticos são distintos em diferentes crianças; $3^{\text {a }}$ ) o negativismo é uma característica marcante. Esses períodos, portanto, são caracterizados por uma atitude de negativismo com relação às exigências antes cumpridas: as crianças tornam-se desobedientes, caprichosas, contestadoras, e, muitas vezes, entram em conflito com os adultos que as cercam, geralmente com os pais e professores. Bozhóvich (1987, p. 255) reforça essa idéia afirmando que todas as peculiaridades das crianças que vivem um período crítico indicam frustração, que surge como uma resposta à privação de algumas necessidades essenciais ao sujeito. Portanto, o autor conclui que essa reação de frustração ocorre quando as crianças não satisfazem suas necessidades ou quando, inclusive, reprimem ativamente aquelas novas necessidades que surgem no final de cada etapa de desenvolvimento.

No desenvolvimento de períodos críticos, com relação aos períodos estáveis, “(...) passam ao primeiro plano os processos de extinção e retirada, decomposição e desintegração de tudo que se havia formado na etapa anterior e caracterizava a criança de dita idade. A criança perde o que já tinha conseguido antes de adquirir algo novo" (Vygotski, 1996, p. 257). Ela perde os interesses que ultimamente ocupavam a maior parte de seu tempo e atenção, e agora é como se houvesse um esvaziamento das formas de suas relações externas, assim como de sua vida interior.

Os períodos de crise que se intercalam entre os estáveis, “(...) configuram os pontos críticos, de mudança no desenvolvimento, confirmando uma vez mais que o desenvolvimento da criança é um processo dialético em que a passagem de um estágio a outro não se realiza pela via evolutiva, senão revolucionária” (idem, ibid., p. 258). As crises mostram a necessidade interna das mudanças de estágios, da passagem de um estágio a outro, pois surge uma contradição aberta entre o modo de vida da criança e as suas possibilidades que já superaram esse modo de vida. No entanto, de acordo com Leontiev (1998a), essas crises não são inevitáveis: o que são inevitáveis são os 
momentos críticos, a ruptura, as mudanças qualitativas no desenvolvimento. É por isso, segundo Leontiev (1978), que atividade se reorganiza. As necessidades internas e externas levam a criança a mudar de interesse, a formarem-se novas atividades dominantes, num processo dialético entre o "velho" e o "novo" em termos de capacidades, habilidades, aspirações e formações psicológicas. Utilizando, neste aspecto, as palavras de Davidov (1988), podemos dizer que o que era uma atividade principal, na passagem de um estágio para outro, torna-se "latente", exercendo uma influência "subterrânea".

Para Vygotski (1996) as idades constituem formações globais e dinâmicas e as estruturas determinam o papel e o peso específico de cada linha parcial de desenvolvimento. Em cada período de idade não se modificam, no transcorrer do desenvolvimento, aspectos isolados da personalidade da criança. A personalidade da criança modifica-se em sua estrutura interna como um todo e as leis que regulam esse todo determinam a dinâmica de cada uma de suas partes. Por esse motivo, em cada etapa de idade encontramos sempre uma nova formação central (ou neoformação) que funciona como uma espécie de guia para todo o processo de desenvolvimento que caracteriza a reorganização de toda a personalidade da criança sobre uma base nova. A estrutura de cada idade anterior transforma-se em uma nova que surge e se desenvolve à medida que ocorre o desenvolvimento da criança. Para entender essa estrutura é fundamental levar em consideração que a relação entre o todo e a parte é uma relação dinâmica que determina as mudanças e o desenvolvimento tanto do todo como das partes.

Por meio de suas pesquisas Vygotski (1996), concluiu que, na análise da evolução do desenvolvimento infantil, é preciso, pois: 10) estudar a dinâmica da idade para esclarecer como a situação social influencia nas novas estruturas da consciência da criança nos diversos períodos evolutivos; $2^{\circ}$ ) estudar a origem ou gênese das novas formações centrais de determinada idade; $3^{\circ}$ ) estudar as conseqüências advindas dessas novas estruturas de idades, pois a nova estrutura da consciência adquirida significa que a criança percebe distintas maneiras em sua vida interior, assim como o mecanismo interno de suas funções psíquicas; e $4^{\circ}$ ) observar, além das transformações internas, a mudança de comportamento na relação com outras pessoas, pois essa reestruturação da situação social de desenvolvimento constitui o conteúdo principal das idades críticas. 
A periodização do desenvolvimento psicológico individual na perspectiva...

Consideramos importante apresentar, a título de esclarecimento, a lei fundamental da dinâmica das idades, propostas por Vygotski (ibid., p. 265):

(...) as forças que movem o desenvolvimento da criança em uma ou outra idade acabam por negar e destruir a própria base de desenvolvimento de toda idade, determinando, com a necessidade interna, o fim da situação social do desenvolvimento, o fim da etapa dada de desenvolvimento no passo seguinte, ou ao período superior de idade.

\section{Considerações finais}

Com relação à periodização do desenvolvimento, a psicologia russa tomou como base as idéias elaboradas por Vigotski sobre o problema das idades e as crises pelas quais passam a criança no desenvolvimento ontogenético de sua personalidade. Nessa perspectiva, a infância tem um caráter histórico concreto e as particularidades, as especificidades de cada idade também são historicamente transformadas. Os autores russos, como Vygotski, Leontiev e Elkonin, propuseram uma periodização do desenvolvimento fazendo referência a uma sociedade socialista.

Os estágios de desenvolvimento, para esses autores, possuem uma certa seqüência no tempo, mas não são imutáveis. Eles dependem das condiçôes concretas nas quais ocorre o desenvolvimento. As condições histórico-sociais concretas exercem influência tanto sobre o conteúdo concreto de um estágio individual do desenvolvimento como sobre o curso total do processo de desenvolvimento psíquico como um todo. Como exemplo, podemos citar a atividade principal do trabalho que, em cada época da sociedade, alonga-se ou não, de acordo com as exigências sociais. Mesmo no caso da atividade de jogo, em determinados lugares, mesmo no Brasil, onde já foi constatado o grande índice de crianças que trabalham, não podemos dizer que essa atividade seja a dominante no período pré-escolar, pois os limites de idade de cada estágio também dependem das condições históricas concretas nas quais está ocorrendo o desenvolvimento da criança. Esses limites de idade se alteram com a mudança das condiçôes histórico-sociais. Portanto, Elkonin (1998, p. 81) levanta a conjectura de que "(...) os processos do desenvolvimento psíquico que se operam em certos períodos da infância aparecerão e mudarão na história”. 
Elkonin (1987, p. 12-124) ressalta que a importância teórica e prática das hipóteses sobre o caráter periódico dos processos de desenvolvimento psíquico e do esquema de periodização construído sobre essa base permite: a) superar a divisão entre aspectos motivacionais e das necessidades, e intelectual-cognitivo; b) considerar o desenvolvimento psíquico desenvolvendo-se segundo uma espiral ascendente e não linear; c) analisar as vinculações existentes entre os períodos isolados para, então, estabelecer a importância funcional de todo período precedente para o início do seguinte; e d) finalmente, essa hipótese está orientada a dividir o desenvolvimento psíquico em épocas e estádios de tal forma que corresponda às leis internas de desenvolvimento, vinculados a fatores externos, às necessidades que a realidade externa propóe aos sujeitos.

$\mathrm{Na}$ prática, esses conhecimentos ajudam a solucionar a questão sobre a forma como as crianças, em alguns períodos de desenvolvimento infantil, reagem a determinadas influências do ensino e mesmo sobre a forma como o ensino é organizado na nossa sociedade. Leontiev (1978) afirma que as próprias crises em cada etapa de desenvolvimento podem ser superadas, ou mesmo podem deixar de existir se o processo educativo for racionalmente conduzido, se houver uma direção no sentido de já levar em consideração as estruturas mentais que estão sendo elaboradas no período de transição de um estágio para o outro.

Kostiuk (1991, p. 20) entende que aprendizagem e educação têm muito em comum e que conduzir o desenvolvimento por meio da educação "(...) significa organizar esta interação, dirigir a atividade da criança para o conhecimento da realidade e para o domínio por meio da palavra - do saber e da cultura da humanidade, desenvolver concepções sociais, convicções e normas de comportamento moral". Neste aspecto, podemos nos voltar para a teoria de Vigotski que aborda a relação entre desenvolvimento e aprendizagem, enfocando o desenvolvimento próximo. $\mathrm{Na}$ abordagem histórico-cultural, o aprendizado é considerado um aspecto fundamental para que as funções psicológicas superiores aconteçam; dessa forma o ensino é fator imprescindível para o desenvolvimento do psiquismo humano.

Para Vigotski (1993, 1998) existem relações complexas entre desenvolvimento e aprendizagem. Esse autor identificou dois níveis de desenvolvimento. O primeiro nível é denominado de desenvolvimento real ou efetivo. Ele é constituído pelas funçôes psicológicas já 
A periodização do desenvolvimento psicológico individual na perspectiva...

efetivadas. O segundo nível é o desenvolvimento próximo e define-se como aquelas funções que estão em vias de amadurecer e que podem ser identificadas por meio da solução de tarefas com o auxílio de adultos e outras crianças mais experientes. Ao passo que aquele nível caracteriza o desenvolvimento mental, retrospectivamente, este o caracteriza prospectivamente. À medida que ocorre a interação com outras pessoas, a criança é capaz de movimentar vários processos de desenvolvimento que, sem ajuda, seriam impossíveis de ocorrer. Vygotski (1993, p. 239) ressalta que "(...) a zona de desenvolvimento próximo tem um valor mais direto para a dinâmica da instrução que o nível atual de seu desenvolvimento". Portanto, o ensino deve incidir sobre essa zona de desenvolvimento e as atividades pedagógicas precisam ser organizadas, com a finalidade de conduzir o aluno à apropriação dos conceitos científicos elaborados pela humanidade.

Davidov (1988) enfatiza a necessidade de a educação ser guiada pelo princípio do desenvolvimento, isto é, que haja uma sistematização da educação de forma que esta possa dirigir regularmente os ritmos e o conteúdo do desenvolvimento por meio de ações que exercem influência sobre este. Dessa forma, o ensino deve realmente promover o desenvolvimento e criar nas crianças as condiçóes e premissas do desenvolvimento psíquico. Neste processo, o professor tem papel destacado como mediador entre o aluno e o conhecimento, cabendo a ele intervir na zona de desenvolvimento próximo dos alunos, conduzindo a prática pedagógica. Portanto os educadores, de uma forma geral, precisam estar atentos às peculiaridades do desenvolvimento psíquico em diferentes etapas evolutivas, para que possam estabelecer estratégias que favoreçam a apropriação do conhecimento científico. Neste sentido, Kostiuk (1991) ressalta que é necessário que o professor tenha clareza de como o ensino influi sobre o desenvolvimento intelectual e das características psicológicas dos alunos, e que se estudem maneiras de valorizar a eficácia dos diversos métodos de ensino no desenvolvimento do pensamento, da memória e de outros processos mentais.

O desenvolvimento do aluno não ocorre, segundo Davidov \& Márkova (1987a, 1987b), pela assimilação de qualquer conceito ou habilidade particular; o desenvolvimento ocorre quando existem avanços qualitativos no nível e na forma das capacidades e nos tipos de atividades, de que se apropria o indivíduo. A atividade especial 
do escolar deve estar fixada na experiência histórico-social - nos objetos da cultura humana, nas diversas esferas de conhecimento e na ciência -; são os conhecimentos científicos que devem ser apropriados pelos alunos levando-se a pertencer ao gênero humano.

De acordo com Leontiev (1978), desenvolvendo-se, a criança passa a atuar como membro da sociedade, portadora de obrigaçôes que esta lhe impõe e os estádios sucessivos do seu desenvolvimento são de fato graus diferentes dessa transformação. Como afirmamos no decorrer deste trabalho, o homem apropria-se do mundo dos objetos por meio das relaçóes reais que estabelece com o mundo. Essas relações são determinadas pelas condições históricas concretas, sociais, nas quais o homem se desenvolve e também pela maneira como a sua vida se forma nessas condições e como ele se apropria das objetivaçôes já produzidas e transmitidas por intermédio da educação.

Recebido em novembro de 2003 e aprovado em março de 2004.

\section{Notas}

1. Em nossa dissertação de mestrado (Facci, 1998) e em nossa tese de doutorado, que foi defendida em 2003 - e que será publicada em 2004 -, tivemos a oportunidade de aprofundar nossos estudos da psicologia vigotskiana.

2. Em espanhol esse conceito é traduzido como "actividad rectora". Em português esse conceito é traduzido por "atividade principal" ou como "atividade dominante"; optamos por utilizar neste texto a primeira expressão.

\section{Referências bibliográficas}

BOZHÓVICH, L. Las etapas de formación de la personalidad en la ontogenesis. In: Davidov, V; SHUARE, M. (Org.). La psicología evolutiva y pedagógica en la URSS (antologia). Moscou: Progresso, 1987. p. 250-273.

DAVIDOV, V. La enseñanza escolar y el desarrollo psíquico. Moscou: Progresso, 1988.

DAVIDOV, V.; MÁRKOVA, A. El desarrollo del pensamiento en la edad escolar. In: Davidov, V; Shuare, M. (Org.). La psicología evolutiva y pedagógica en la URSS (antologia). Moscou: Progresso, 1987a. p. 173-193. 
A periodização do desenvolvimento psicológico individual na perspectiva...

DAVIDOV, V.; MÁRKOVA, A. La concepción de la actividad de estudio de los escolares. In: Davidov, V; Shuare, M. (Org.). La psicología evolutiva y pedagógica en la URSS (antologia). Moscou: Progresso, 1987b. p. 316-336.

DAVIDOV, V; SHUARE, M. (Org.). La psicología evolutiva y pedagógica en la URSS (antologia). Moscou: Progresso, 1987.

DUARTE, N. Educação escolar, teoria do cotidiano e a escola de Vigotski. Campinas: Autores Associados, 1996.

DUARTE, N. Vigotski e o "aprender a aprender": crítica às apropriações neoliberais e pós-modernas da teoria vigotskiana. Campinas: Autores Associados, 2000.

ELKONIN, D. Sobre el problema de la periodización del desarrollo psíquico en la infancia. In: Davidov, V; Shuare, M. (Org.). La psicología evolutiva y pedagógica en la URSS (antologia). Moscou: Progresso, 1987. p. 125-142.

ELKONIN, D. Psicologia do jogo. São Paulo: Martins Fontes, 1998.

FACCI, M.G.D. O psicólogo nas escolas municipais de Maringá: a história de um trabalho e a análise de seus fundamentos teóricos. 1998. 251f. Dissertação (Mestrado) - Universidade Estadual Paulista, Marília.

FACCI, M.G.D. Valorização ou esvaziamento do trabalho do professor?: um estudo crítico-comparativo da Teoria do Professor Reflexivo, do Construtivismo e da Psicologia Vigotskiana. Campinas: Autores Associados, 2004.

KOSTIUK, G.S. Alguns aspectos da relação recíproca entre educação e desenvolvimento da personalidade. In: LuRIA, A.R. et al. Psicologia e pedagogia: as bases psicológicas da aprendizagem e do desenvolvimento. São Paulo: Moraes, 1991.

LEONTIEV, A.N. O desenvolvimento do psiquismo. Lisboa: Livros Horizonte, 1978.

LEONTIEV, A.N. El desarrollo psíquico del niño en la edad preescolar. In: Davidov, V; Shuare, M. (Org.). La psicología evolutiva y pedagógica en la URSS (antologia). Moscou: Progresso, 1987. p. 57-70 
LEONTIEV, A.N. Uma contribuição à teoria do desenvolvimento da psique infantil. In: Vigotski, L.S.; Luria, A.R.; LeontieV, A.N. Linguagem, desenvolvimento e aprendizagem. 6. ed. São Paulo: EDUsP, 1998a. p. 59-83.

LEONTIEV, A.N. Os princípios psicológicos da brincadeira pré-escolar. In: Vigotski, L.S.; Luria, A.R.; LeOnTIEV, A.N. Linguagem, desenvolvimento e aprendizagem. 6. ed. São Paulo: EDUSP, 1998b. p. 119-142.

PALÁCIUS, J. Introdução à psicologia evolutiva: história, conceitos básicos e metodologia. In: Coll, C.; Palácius, J.; Marchesi, A. (Org.). Desenvolvimento psicológico e educação. Porto Alegre: Artes Médicas, 1995. v.1. p. 9-26.

SHUARE, M. La psicología soviética tal como yo la veo. Moscou: Progresso, 1990.

TULESKI, S.C. Vygotski: a construção de uma psicologia marxista. Maringá: EDUEM, 2002.

VIGOTSKI, L.S. Linguagem e desenvolvimento intelectual na idade escolar. In: Vigotski, L.S.; LuRiA, A.R.; LeOnTIEV, A.N. Linguagem, desenvolvimento e aprendizagem. 6. ed. São Paulo: EDUSP, 1998. p. 103-117.

VYGOTSKI, L.S. Obras escogidas. Madrid: Visor, 1993. v.2.

VYGOTSKI, L.S. Obras escogidas. Madrid: Visor, 1996. v.4.

ZAPORÓZHETS, A. Importancia de los períodos iniciales de la vida en la formación de la personalidad infantil. In: Davidov, V; SHUARE, M. (Org.). La psicología evolutiva y pedagógica en la URSS (antologia). Moscou: Progresso, 1987. p. 228-249. 